\title{
Giant Sacrococcygeal Teratoma in Newborns : Management of Two Cases in an Underdeveloped Country
}

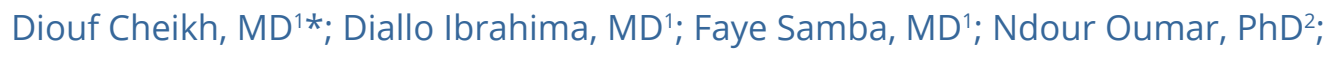 \\ Sow Omar, MD; Ngom Gabriel, MD, PhD²
}

'Department of Surgery and Specialties, Ziguinchor University, Ziguinchor, Senegal

${ }^{2}$ Department of Surgery and Specialties, Cheikh Anta Diop University, Dakar, Senegal

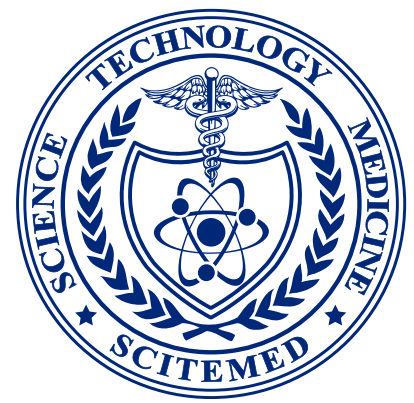

\begin{abstract}
The sacrococcygeal teratomas are rare benign tumors derived from totipotent embryonic cells of the caudal region. The purpose of this article is to report our experience in management of two cases of giant sacrococcygeal teratomas in Ziguinchor Regional Hospital and emphasize the need for prenatal diagnosis and management before complications.
\end{abstract}

\section{Introduction}

Sacrococcygeal teratomas are benign tumors derived from totipotent embryonic cells of the caudal region [1]. Their incidence is estimated to be between $1 / 35000$ and 1/40000 births [1-4]. Diagnosis and management of these tumors are ideally done in the antenatal period $[2,3,5]$. Nevertheless, complications including rupture in case of vaginal delivery and degeneration, especially after the age of 4 months of these tumors, are possible [1-3]. The purpose of this study is to report two cases of giant sacrococcygeal teratomas in Ziguinchor Regional Hospital with successful management and emphasize the need for prenatal management before complications.

\section{Case Reports}

\section{Case 1}

A 29-year-old mother, G5 P5, delivered a female newborn in the emergency for sacrococcygeal mass. An ultrasound performed at the third quarter of pregnancy highlighted a sacrococcygeal tumor and pregnancy monitoring had been advocated. On examination, it was found that the female newborn had a birth weight of $3.800 \mathrm{~kg}$ and head circumference of $32 \mathrm{~cm}$. The Apgar score was $8 / 10$ in the first minute and 9/10 in the fifth minute. Physical examination revealed a giant sacrococcygeal tumor measuring $20 \mathrm{~cm}$ long (Figure 1). Echocardiography was normal. The abdominal ultrasound confirmed a sacrococcygeal teratoma stage I of Altman classification. Hemoglobin level was $10.2 \mathrm{~g} / \mathrm{dL}$, hematocrit $32.2 \%$, white blood cells $13400 / \mathrm{mL}$, and platelets $258000 \mathrm{mu} / \mathrm{L}$. The dosage of alpha-fetoprotein(AFP) was not possible in our conditions. After resuscitation, a tumor resection was done twelve hours after birth. The newborn received intravenous antibiotics (ceftriaxone $100 \mathrm{mg} / \mathrm{kg}$ ) day, metronidazole $35 \mathrm{mg} / \mathrm{kg} /$ day, and paracetamol $7.5 \mathrm{mg} / \mathrm{kg}$ every 6 hours). The postoperative course was uneventful and the newborn was returned to the family home eight days after surgery. A physical examination was completed by monitoring ultrasound every three months. AFP was done every 6 months. After one year of growth, no problem was detected.

\section{Case 2}

A newborn female was carried to emergency after delivery for a sacroiliac mass coccyx. Her mother was a primigravida of 21 years old. No

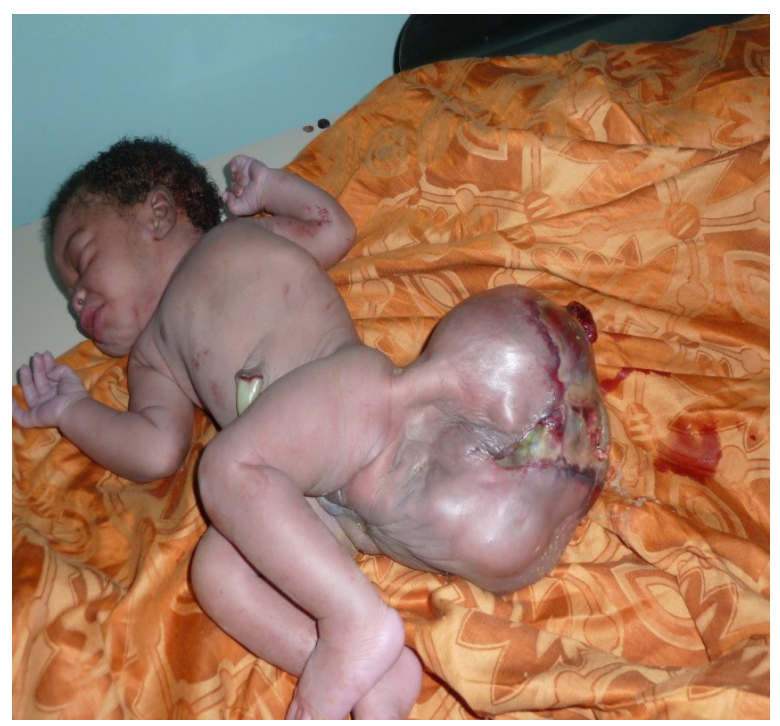

Figure 1. A giant sacrococcygeal tumor.

ultrasound was done during pregnancy. Examination at birth showed a female newborn weighing $3.900 \mathrm{~kg}$. Apgar score was $8 / 10$ in the first minute and $9 / 10$ in the fifth minute. A sacrococcygeal mass of $25 \mathrm{~cm}$ long axis was found. Echocardiography was normal and the abdominal ultrasound confirmed a sacrococcygeal tumor stage I of Altman classification. Blood count showed a hemoglobin level of $15.2 \mathrm{~g} / \mathrm{dL}$, hematocrit of 39.2 $\%$, white blood cell count $10400 / \mathrm{mL}$, and platelets $200000 \mathrm{mu} / \mathrm{L}$. Blood group was O-Rh positive. Due to unavailability of AFP, a surgery decision of resection was taken. A one-piece removal of the tumor and coccyx was done under general anesthesia, twelve hours after birth (Figure 2). Antibiotics were given intravenously (amoxicillin and clavulanic acid 80 $\mathrm{mg} / \mathrm{kg} /$ day, paracetamol $7.5 \mathrm{mg} / \mathrm{kg}$ every 6 hours). After successful management, the newborn baby was discharged from the hospital six days after surgery. A physical examination was completed by monitoring ultrasound every three months. The blood level of AFP was recorded every 6 months. No problem was detected after six months of growth. 


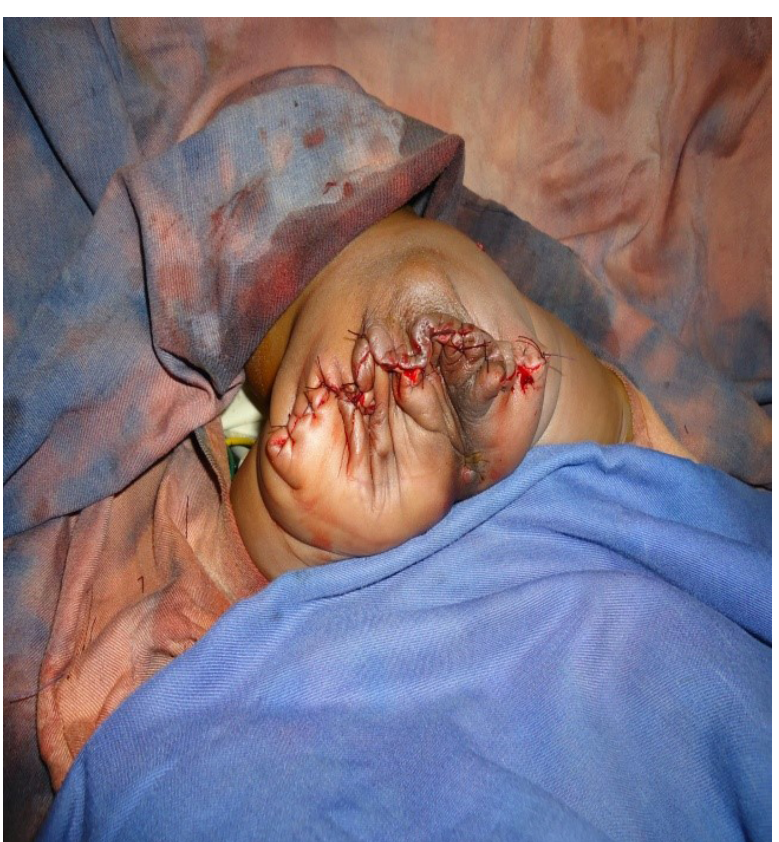

Figure 2. A giant sacrococcygeal tumor after surgical resection.

\section{Discussion}

The sacrococcygeal teratomas are multi-tissue tumors composed of varying proportions in tissues from all three germ layers (endoderm, ectoderm, and mesoderm) [6]. Their frequency of occurrence varies from 1 in 28,500 to 40,000 births and is found more frequently in the female subject with a sex ratio of $1 / 3$ to $1 / 4[1,2,3,7,5]$. This epidemiological parameter was verified in our study where both cases were reported in female subjects.

Sacrococcygeal tumor can be discovered in three circumstances. The ideal circumstance is an antenatal diagnosis by ultrasound or magnetic resonance imaging [5]. One of our patients was diagnosed in prenatal period through an obstetric ultrasound. This diagnosis in the neonatal period allowed an early management by intrauterine or neonatal surgery $[2,3,5]$. The second circumstance of discovery is an emergency delivery of a newborn with sacrococcygeal mass. This condition was found in our second patient. The third circumstance is a malignant sacrococcygeal tumor which can be associated with local or loco-regional metastasis. Physical examinations completed by ultrasound and scanner are used to classify the tumor according to the four stages of Altman [2,6]. Our two patients were of stage I of Altman classification. The dosage of AFP is important for the diagnosis of sacrococcygeal teratoma after surgery. AFP has a good predictive value for the presence of residual tumor [2]. However, in our working condition, its measurement was not available in our department.

The treatment of sacrococcygeal tumors is mainly surgical and consists of resection of the tumor with the coccyx [1-9]. This resection in stage I tumors can be made exclusively by perineal incision while a combined abdominal and perineal approach may be necessary for other types $[2,3,6]$. In our two patients, the surgical excision was made by an exclusive perineal incision. The period of surgical resection is the crucial element in the evolution of the disease. The neonatal period or before two months of age is the ideal time for this surgery as observed in our two patients $[2,3,6]$. Delayed surgery is associated with a higher rate of recurrence or malignancy [2]. For some, the degeneration rate is estimated between 7 and 10\% when resection is performed early (before the age of two months). However, it goes up to 48 to $67 \%$ in patients operated after two months of age [2]. In the study of Rangsan incidence of malignant, sacrococcygeal tumor was $2.4 \%$ in the patients operated

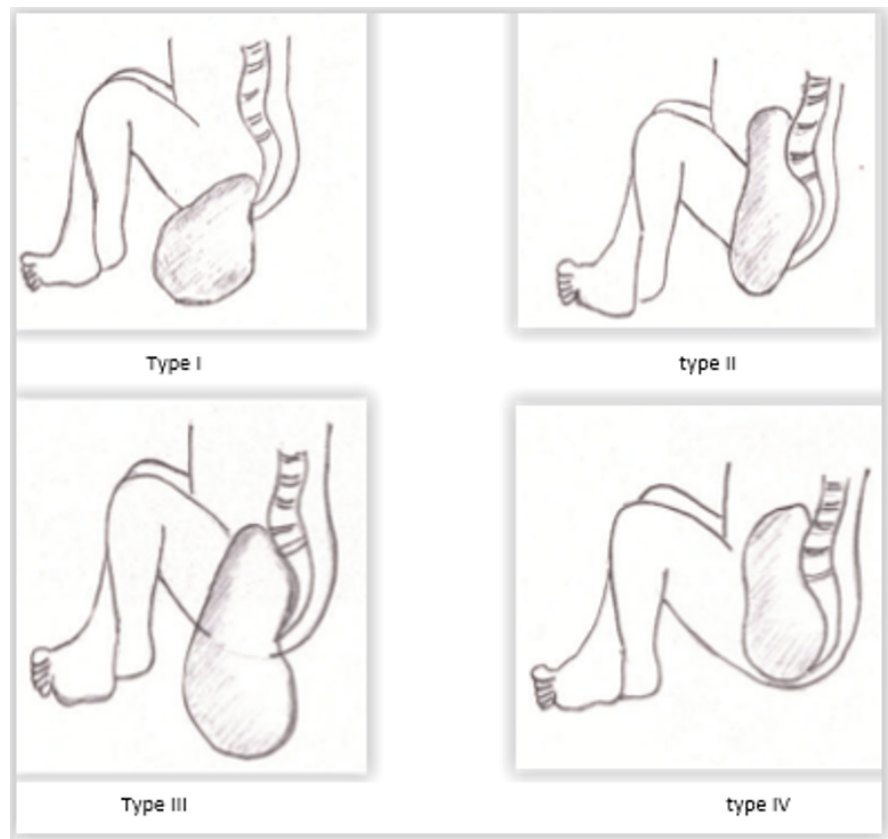

Figure 3. Altman classification of sacrococcygeal teratomas.

within a year, while it was $73.3 \%$ among the patients operated after the age of one year [2].

The type of tumor is also an important factor in the occurrence of degeneration of sacrococcygeal tumors. The type I of Altman classification (Figure 3 ) is associated with a low risk of malignant changes while type IV presents the highest risk of malignancy [2]. The prognosis of sacrococcygeal teratomas is variable. Benachi established a prognosis classification into three groups in premature. Group A represents tumors less than $10 \mathrm{~cm}$ or avascular moderately vascularized with slow growth; group B with tumors above $10 \mathrm{~cm}$ with marked vascularity associated with heart failure and rapid growth; and group $C$ with tumors of $10 \mathrm{~cm}$ or more in cystic predominance moderately vascularized with slow growth [9]. Other less important prediction elements are represented by a discovery of the tumor before 20 weeks of gestation, childbirth before 30 weeks of gestation, a lower Apgar score of 7 in the fifth minute, and a low birth weight or hydramnios [3,9]. In newborns, at time, sacrococcygeal tumor prognosis essentially depends on the volume of the tumor vascularization and the presence of other malformations [2,3]. A large tumor is exposed to the risk of breakage during the delivery or extraction during a cesarean. Basically, the hypervascularization makes the removal difficult and subject to surgical hemorrhagic risk. Regarding giant tumors, the risk of rupture and the possibility of tumor residuals are haunting the pediatric surgeon. In the medium and long-term, sacrococcygeal tumor prognosis is conditioned not only by the recurrence but also the anorectal or functional urinary sequelae $[2,3]$. These risks of recurrences require a constant monitoring of patients clinically and dosage of AFP [13]. These recurrences are observed in about $10-20 \%$ over the first three years of life, and $40 \%$ in the form of malignant tumors. These findings explain the necessity of monitoring patients for at least 3.5 years after surgery $[2,3]$.

\section{Conclusion}

The sacrococcygeal teratomas are rare germ cell tumors whose diagnosis in antenatal period is possible with ultrasound and magnetic resonance imaging. They come in four clinical aspects. Their only surgical treatment gives a good result especially in the neonatal period. A misbehaving surgery exposes the risk of recurrence and malignant degeneration. 


\section{CASE REPORT}

\section{Article Information}

*Correspondence: Diouf Cheikh, MD

Department of Surgery and Specialties, Ziguinchor University, Ziguinchor, Senegal.

Email: cdiouf37@gmail.com

Received: Nov. 08, 2017; Accepted: Dec. 16, 2017; Published: Apr. 20, 2018

DOI: 10.24983/scitemed.aspm.2018.00056

Copyright (c) 2018 The Author (s). This is an open-access article distributed under the terms of the Creative Commons Attribution 4.0 International License (CC-BY)

\section{Funding: None}

\section{Conflict of Interest Disclosures: None}

Informed Consent: Written informed consent was obtained from parents whose children participated in this case.

\section{Keywords}

Antenatal; perineal; resection; teratoma.

\section{References}

1. Moifo B, Mouafo Tambo F, Nguefack S, Sandoz Z, Abogo S, Gonsou Fostin J. Sacrococcygeal teratoma of delayed diagnosis: clinical and radiological features of two cases and therapeutic considerations.
Mali Medical 2014;1:53-57.

2. Niramis R, Anuntkosol M, Buranakitjaroen V, et at. Long-term outcomes of sacrococcygeal germ cell tumors in infancy and childhood. Surgery Research and Practice 2015;2015:398549.

3. Gangadharan M, Panda S, Almond PS, Agrawal V, Bhandari A, Koska AJ. Management of preterm giant sacrococcygeal teratoma (GSCT) with an excellent outcome. Journal of Surgical Case Reports 2014;12:rju132.

4. Sheng QS, Xu XM, Cheng XB, Wang WB, et al. Multistage resection and repair for the treatment of adult giant sacrococcygeal teratoma: a case report and literature review. Oncology Letters 2015;10:425429.

5. Adekola H, Mody S, Bronshtein E, Puder K, Abramowicz JS. The clinical relevance of fetal MRI in the diagnosis of Type IV cystic sacrococcygeal teratoma-a review. Fetal and Pediatric Pathology 2015;34:3143.

6. Ndour O, Ngom G, Faye Fall A, et al. Aspects épidémiologiques, diagnostiques et thérapeutiques du tératome sacro-coccygien chez l'enfant : analyse de 11 observations. Medecine d'Afrique Noire 2008;55(12):641-647.

7. Chagou M, Bernoussi K. Sacrococcygeal teratoma: report of a case. Pan African Medical Journal. 2015;20:160.

8. Ouattara O, Dieth A, Kouame B, et al. Degenerated sacrococcygeal teratoma a test of chemotherapy. Medecine d'Afrique Noire 1997;44(3):181-182.

9. Benachi A, Durin L, Vasseur Maurer S, et al. Prenatally diagnosed sacrococcygeal teratoma: a prognostic classification. Journal of Pediatric Surgery 2006;41:1517-1521. 